\title{
FOREST DEGRADATION ANALYSIS USING GEOSPATIAL TECHNIQUES APPROACH IN TROPICAL REGION OF PAHANG, MALAYSIA
}

\author{
M. A. Othman, Z. H. Ash'aari*, A. Z. Aris, M. F. Ramli \\ Dept. of Environmental Sciences, Faculty of Environmental Studies, Universiti Putra Malaysia, 43400 UPM Serdang, Selangor, \\ Malaysia-mohamadalekhwan@gmail.com, (zulfa, zaharin, firuz)@upm.edu.my
}

KEY WORDS: Degradation, Forest, Land Change Modeler, MLC, Peat Swamp

\begin{abstract}
:
Tropical forest degradation is a global concern since most deforestation study supports that the region seems to suffer a great loss in the recent decades. The main objective of this paper is to evaluate the forest dynamic in Rompin and Pekan district of Pahang state using satellite image and land use model. Pekan district has the biggest peat swamp forest (PSF) in Peninsular Malaysia and also covers with inland dipterocarp forest. The land use of study area was categorized using Maximum Likelihood Classification (MLC) and further analysed using Land Change Modeler (LCM). From the results, forest land use has a negative growth (15\% net loss) in the last 25 years, mostly converted to other vegetation class with overall $45 \%$ loss and $20 \%$ gain. The PSF itself was continuously degraded during the 1990 to 2017 periods, with a total loss of more than $700 \mathrm{~km} 2$. This study demonstrates the forest land use exploitation and the needs to consider a details forest monitoring analysis to extract the actual contributors for this phenomenon. The role of Permanent Reserved Forest (PRF) seem likely to be taking effect since the deforestation only massively happen outside of the PRF and part of the disturbed area are being reforested.
\end{abstract}

\section{INTRODUCTION}

\subsection{Background}

Tropical forest monitoring is on a high demand for its data and information since it has been one of the international goals and national commitments (Petersen et al., 2018). Forest conservation and management, climate change, and sustainable development required credible, accurate, and reliable monitoring of changes in forest extent and carbon stocks.

Remotely sensed data are extensively used in forest land cover change mapping and as one of its main areas of application (Otukei and Blaschke, 2010). Satellite data and other remote sensing methods rapid development has enable better forest monitoring. The advance of this technology at the time now has shown a wide spread applications of satellite imagery in many fields as a part of research tools. The basic principle of remote sensing involved types of data collected which can be of many forms such as variations in force distributions, acoustic wave distributions, or electromagnetic energy distributions. Satellite for image acquisition acquires data on the variations of electromagnetic energy distributions similar on how our eyes captures data to display our sight. In a rapid changing technology of remote sensing, numerous countries and commercial firms have been developing and launching new systems (Lillesand et al., 2008). As in 2019, more satellite imageries with higher resolution have been developed to produce more clear view of the surface features and provide assist in time-series forest monitoring, but differ in accessibility, cost, and processing techniques.

Referring to (Islam, Ahmed, 2011), Land Change Modeler (LCM) is a module that can be used to analyze land cover change as it can evaluate the trend of the change from one land category to another. LCM is a useful tool that can be used to rapidly assess gains and losses in land cover classes, land cover persistence, transitions between categories, and to make LULC change predictions (Leh et al., 2013). It uses a three-stage (change assessment, transition potential modeling and change prediction) process to model land cover change between two time periods and to predict the future land cover. The change analysis panel provides a quantitative assessment of change by illustrating gains and losses by land cover categories. A second option, the net change result is shows by taking the earlier land cover areas, adding the gains and then subtracting the losses. The third option is to examine the contributions to changes experienced by single land cover. However, only the change assessment part will be utilised in this study to analyse forest degradation status.

\subsection{Problem statement}

Deforestation and forest degradation is a highlighted element in recent decade and need to be assessed due to the main concern from the activities which is emission of carbon, where, (Gibbs et al. 2007) statistically mentioned that approximately up to 25 percent of annual global greenhouse gases (GHG) emissions comes from deforestation and forest degradation. In addition, (Omar et al. 2015) mentioned that living trees contribute the most carbon emission in biomass carbon compared to belowground, deadwood, litter, and soil. Alteration and loss of forests either due to natural and anthropogenic activities can significantly cause the increment of GHG emissions and lastly added to global climate change. Eight billion tons of carbon dioxide were released into the atmosphere from approximately 13 million hectares of deforestation each year (Sasaki et al., 2012), plus, in the 1990s, Southeast Asia successfully have the highest level of deforestation. Therefore, forest activities,

\footnotetext{
* Corresponding author
} 
carbon stock, and modification in the forests in the tropical region need to be periodically assessed.

Deforestation in tropical forest region always has the agricultural activity as the main factor for natural forest disturbance (Barbier, Burgess, 2001; Olaniyi et al., 2012). Agricultural expansion happens mostly in the highly agriculture-dependable economics because of the environment suitability, increase of demands, and profitability, resulting in extension of land area to support the needs. (Hamdan et al., 2016) discussed that most carbon emission Peninsular Malaysia comes from conversion of forest covers to oil palm plantation in period of 2010 to 2015. As a major world's oil palm supplier, it is not surprising that Malaysia try to maximised the export amount of oil palm by increasing the area of plantation, however, end up becoming one of the factors for national forest degradation.

\section{METHODOLOGY}

\subsection{Study area}

The study area located in Rompin and Pekan (RomPek) district of Pahang state, western Peninsular Malaysia (Figure 1). The geographical extent of the area is at: latitude $\left(3^{\circ} 00^{\prime} 0^{\prime \prime}\right) \mathrm{N}$ and

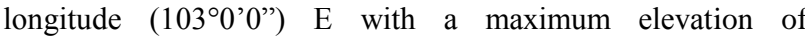
approximately 1020 meters, mostly a flat lowland area. The area covers with majority of oil palm plantation, peat swamp forest (PSF), and inland dipterocarp forest. RomPek district has the most coverage of PSF in Peninsular Malaysia with over half of it located within Production Forest Reserve (Jusoff, Hassan, \& Hamzah, 2007). However, over the last two decades the forest land covers experienced changes in extent due to development and economic expansion. Study by (Othman et al., 2018) using NDVI analysis and (Shevade et al., 2017), revealed that most degradation of forest land cover happened in the area from 2000 to 2015 in Pahang state. Most of the forest cover was converted into other land use mainly to agricultural area and few are due to wood log extraction. Therefore, it is essential to do monitoring of the land cover dynamics in the area for better understanding of current situation and upcoming impacts from the continuation.

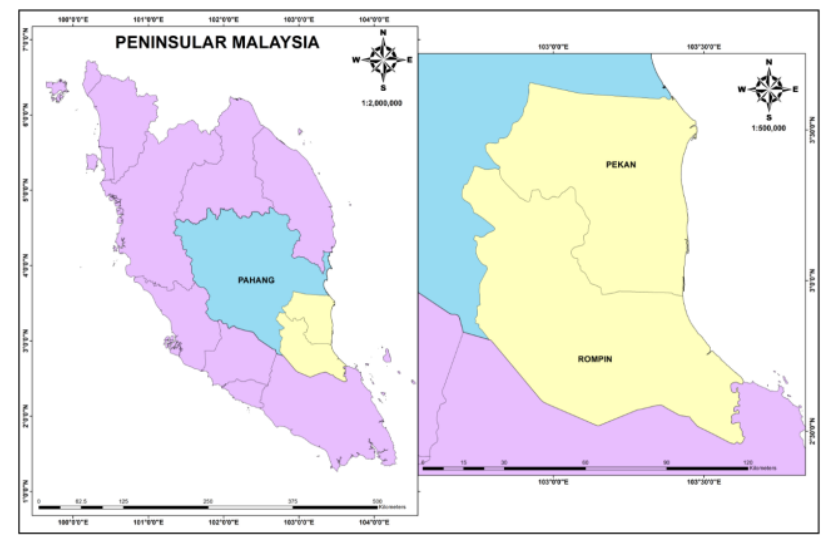

Figure 1. Location of Rompin and Pekan district in Eastern region of Peninsular Malaysia

\subsection{Data acquisition}

The Landsat imageries were assessed from the EarthExplorer website under United State Geological Survey (USGS), courtesy from the NASA Landsat program. Only Landsat 5 (TM) datasets were available and suitable for the selected study area for year 1990, 2000 and 2010 (path 126, row 58). The images were acquired from the most less cloud coverage at the study area with an average of $17 \%$ for $1990,25 \%$ for 2000 and $15 \%$ for 2010 . They were closely dated (in terms of season) and it is expected that there will be no significant spectral differences between the images. Meanwhile, for year 2017, the Landsat 8 OLI image was retrieved from Global Forest Watch website as there is no best available dataset for the year or at least to represent the year. Land use maps of study area from Malaysian Department of Agriculture (DOA) and Google Earth were used as base image for classification reference and accuracy assessment.

\subsection{Pre-processing}

The images were calibrated and the methods were performed using ENVI 5.2 involving the radiometric, atmospheric, and geometric calibration. Some of the image especially the early periods need to be treated with cloud mask to remove cloud disturbance that existed in the area.

\subsection{Image Classification}

A maximum likelihood classification (MLC) algorithm is one the supervised classification method known in image analysis. According to research purpose as well as vegetation type in study area, five classes of forest, other vegetation, residential, open land, and waterbodies were identified. To classify the LULC from a satellite image, a training set of data for the associated classes were first prepared. A group of sample site, known as Area of Interest (AOI), was created from a visual judgement based on the class definition and was carefully selected for each of classes and produces a signature file. The forest land use was defined using literature from Finally, the MLC algorithm was run to produce the LULC classes. The algorithm used the training sample to predict the similar characteristic of the AOI and the image pixels to classify the imageries into an understandable, well grouped land use map. Besides, a post-classification improvement also done using Majority Filter methods to treat data in some area using eight neighbours' rules. Finally, the PSF coverage was extracted from the classified image and analysed.

\subsection{Land change analysis}

The Land Change Modeler (LCM) analysis has a module to help us to better understand the changes happening between the specify land use period (Islam \& Ahmed, 2011). Under the Change Analysis module, we can extract information on gains and losses, net change, and different change map which we can freely choose to analyse or focus on. In this study, it will focus on the conversion of forest to other land use, therefore, a rule of only forest to other land use will always be selected, and LCM will produce a net change analysis between land use.

\section{RESULTS AND DISCUSSION}

\subsection{Land use change in RomPek}

Table 1, Figure 2, and Figure 3 shows the spatial and temporal dynamics of land use in RomPek area from 1990 to 2017. 


\begin{tabular}{|c|c|c|c|c|}
\hline & $\begin{array}{c}\text { LULC } \\
\mathbf{1 9 9 0}\end{array}$ & $\begin{array}{c}\text { LULC } \\
\mathbf{2 0 1 7}\end{array}$ & \multicolumn{2}{|c|}{$\begin{array}{c}\text { Change between 1990 } \\
\text { and 2017 }\end{array}$} \\
\cline { 2 - 5 } & $(\boldsymbol{\%})$ & $(\boldsymbol{\%})$ & $\mathbf{k m}^{\mathbf{2}}$ & $\mathbf{\%}$ \\
\hline Forest & 49.88 & 33.98 & -1408.38 & -15.90 \\
\hline $\begin{array}{c}\text { Non-forest } \\
\text { vegetation }\end{array}$ & 46.37 & 60.74 & +1273.48 & 14.37 \\
\hline $\begin{array}{c}\text { Open land/ } \\
\text { Built up }\end{array}$ & 2.65 & 4.15 & +132.98 & 1.50 \\
\hline $\begin{array}{c}\text { Water- } \\
\text { bodies }\end{array}$ & 1.10 & 1.13 & +1.92 & 0.03 \\
\hline
\end{tabular}

Table 1. Different land use concentration between 1990 to 2017
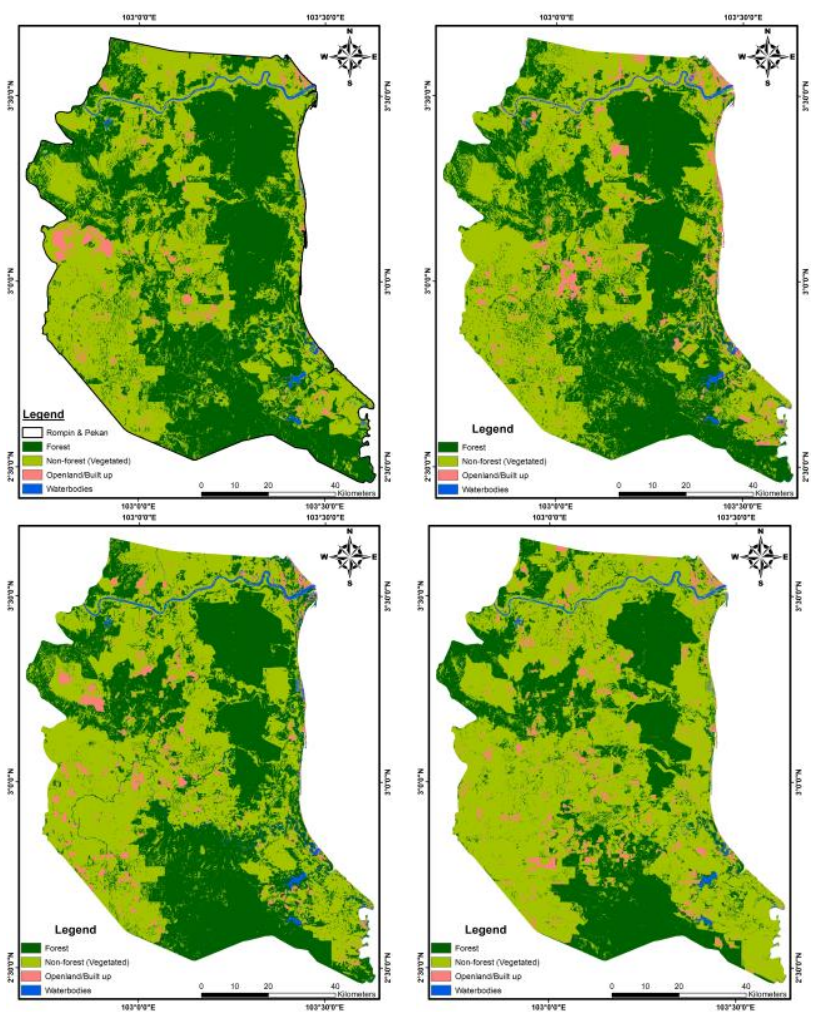

Figure 2. Spatial land use distribution in RomPek district in; (from top left) 1990, 2000, 2010, and 2017

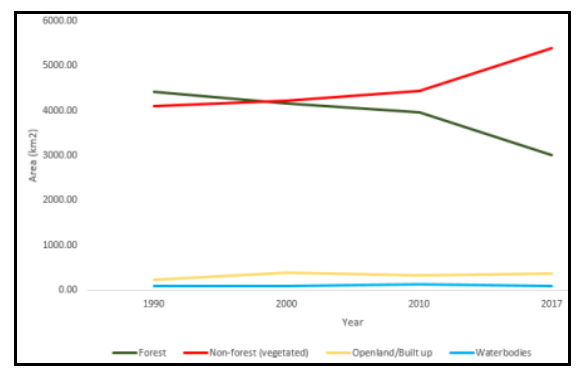

Figure 3. Land use change trend from 1990 to 2017

The forest land use distribution was initially around half of the total area, however, a degradation of $14 \%$ to other vegetation and $1.5 \%$ conversion to built-up and open land area after 25 years. From Table 1, we can conclude that the overall rate of deforestation is $50 \mathrm{~km}^{2} / \mathrm{yr}(0.6 \% / \mathrm{yr})$.

Figure 3 further visualised the exchange of land use category density for the period. The land use change was analysed from the evaluation of gains and losses by classes. Most classes have significant gain and loss, only waterbodies class shows minimal changes of less than $1 \%$. During the period of 1990 to 2017, openland and built up class has loss $81 \%$ and gain $88 \%$. Most of classified open land for all 4 years are actually the interim period for replantation of agriculture. Although the percent of change is big, nonetheless, it involves less than $100 \mathrm{~km}^{2}$ area. In contrast, forest and vegetation each has $44 \%$ and $19 \%$ loss, and $19 \%$ and $38 \%$ gain respectively. Overall change in both class involve area of more than $2000 \mathrm{~km}^{2}$. As referring to (Olaniyi et al., 2012), main contributor for tropical deforestation is agricultural activity, which is also a major problem for global tropical region, and can be apply in the study area.

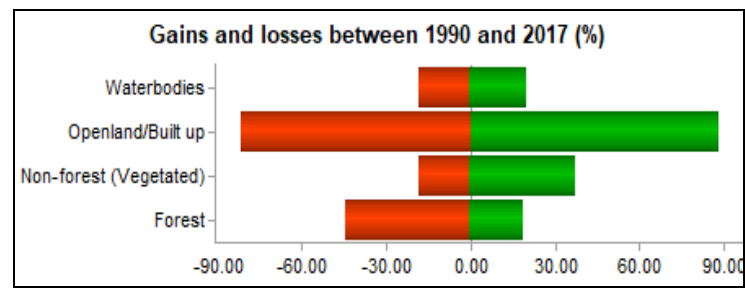

Figure 3. Gain (green) and loss (red) of land use class between 1990 to 2017

\subsection{Forest degradation on peat swamp forest (PSF)}

The result from this approach explain the extreme condition of peatland forest area because they are negatively exponent against time (Figure 4).

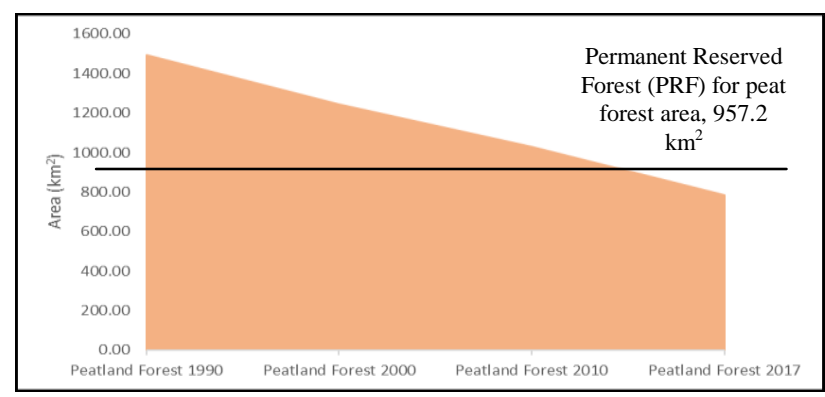

Figure 4. Stacked area illustration of peatland forest density from 1990 to 2017

The rate of reduction for the three time periods is quite similar, ranging from $20-25 \mathrm{~km}^{2} / \mathrm{yr}$, nonetheless, it is quite threatening because it happens continuously without any restoration or afforestation. Originally, in 1990, the PSF having extent approximately $1500 \mathrm{~km}^{2}$, after 28 years, it was halved to 780 $\mathrm{km}^{2}$. (Jusoff et al., 2007) documented that more than half (around $950 \mathrm{~km}^{2}$ ) of PSF in Pekan are located in the Permanent Reserved Forest (PRF), which explained that the forest degradation majorly happens due to deforestation not logging activities because it is all take place outside the protection area. Nevertheless, still there are some part of the PRF suffer from forest conversion. Besides, (Miettinen et al., 2016) also found that industrial plantations extent was developed in the PSF area other than degraded forest between 1990 to 2015. As in 2017, almost all natural peat forest outside of the protection region have extinct. Figure 5 describe the spatial location of the event. 


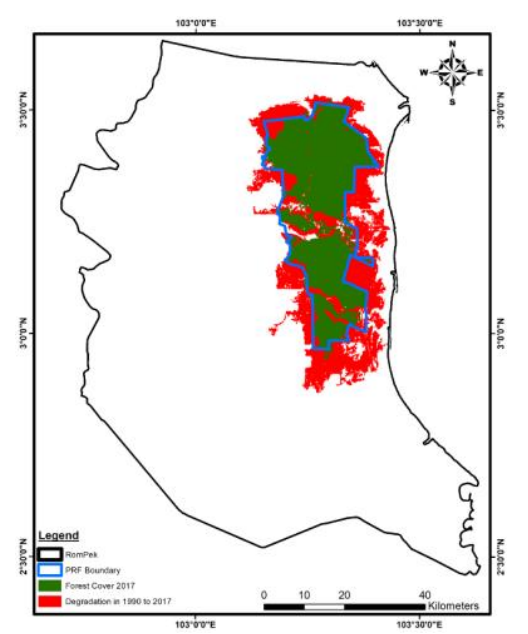

Figure 5. Peat swamp forest spatial degradation

\section{CONCLUSION}

In conclusion, forest land use is an important ecosystem, which can serve as resources and habitat for many species. Therefore, it is a needs for a good management in terms of monitoring the status and control the contributor of deforestation. This study has successfully assessed the forest degradation status in Rompin and Pekan district. The study also quantified the PSF land exploitation in 1990 to 2017. It was found that the rate of deforestation was $50 \mathrm{~km}^{2}$ annually. The total forest conversion was about $1500 \mathrm{~km}^{2}$ and nearly one third of its original extent. LCM is one of a good model to be used for determining land use change. It is simple, but able to describe land use change descriptively and figuratively.

\section{ACKNOWLEDGEMENT}

The author gracefully acknowledge research grant provided by Universiti Putra Malaysia (UPM) under GP-IPS/2016/9506700.

\section{REFERENCES}

Barbier, E. B., \& Burgess, J. C. (2001). The economics of tropical deforestation. Journal of Economic Surveys, 15(3), 413-433.

Gibbs, H. K., Brown, S., Niles, J. O., \& Foley, J. A. (2007). Monitoring and estimating tropical forest carbon stocks: making REDD a reality. Environmental Research Letters, 2(4), 045023 .

Hamdan, O., Rahman, K. A., \& Samsudin, M. (2016, June). Quantifying rate of deforestation and $\mathrm{CO} 2$ emission in Peninsular Malaysia using Palsar imageries. In IOP Conference Series: Earth and Environmental Science (Vol. 37, No. 1, p. 012028). IOP Publishing.

Islam, M. S., \& Ahmed, R. (2011). Land use change prediction in Dhaka city using GIS aided Markov chain modeling. Journal of Life and Earth Science, 6, 81-89.

Jusoff, K., Hassan, C. H., \& Hamzah, K. A. (2007). Tropical peat swamp forest ecosystem and floristic diversity in Pahang,
Malaysia. International Journal of Systems Applications Engineering and Development, 3, 41-44.

Leh, M., Bajwa, S., \& Chaubey, I. (2013). Impact of land use change on erosion risk: an integrated remote sensing, geographic information system and modeling methodology. Land Degradation \& Development, 24(5), 409-421.

Lillesand, T. M., Kiefer, R. W., \& Chipman, J. W. (2008). Digital image interpretation and analysis. Remote sensing and image interpretation, 6, 545-81.

Miettinen, J., Shi, C., \& Liew, S. C. (2016). Land cover distribution in the peatlands of Peninsular Malaysia, Sumatra and Borneo in 2015 with changes since 1990. Global Ecology and Conservation, 6, 67-78.

Olaniyi, A., Abdullah, A. M. M., Ramli, M., \& Sood, A. (2012). Linkage between Economy, Agricultural Land Use and Forest Processes-A Case Study of Selangor, Malaysia. OIDA International Journal of Sustainable Development, 3(9), 21-40.

Omar, H., Chuah, N. M. J., Parlan, I., Samah, A. K. A., \& Musa, S. (2015). Assessing carbon pools in dipterocarp forests of Peninsular Malaysia. J. Trop. Resour. Sustain. Sci, 3, 214221.

Othman, M. A., Ash'aari, Z. H., Aris, A. Z., \& Ramli, M. F. (2018, June). Tropical deforestation monitoring using NDVI from MODIS satellite: a case study in Pahang, Malaysia. In IOP Conference Series: Earth and Environmental Science (Vol. 169, No. 1, p. 012047). IOP Publishing.

Otukei, J. R., \& Blaschke, T. (2010). Land cover change assessment using decision trees, support vector machines and maximum likelihood classification algorithms. International Journal of Applied Earth Observation and Geoinformation, 12, S27-S31.

Petersen, R., Davis, C., Herold, M., \& de Sy, V. (2018). Tropical Forest Monitoring: Exploring the Gaps Between What is Required and What is Possible for REDD+ and Other Initiatives (No. Ending Tropical Deforestation Series, p. 12p). World Resources Institute, Washington, DC, USA.

Sasaki, N., Chheng, K., \& Ty, S. (2012). Managing production forests for timber production and carbon emission reductions under the REDD+ scheme. Environmental Science \& Policy, $23,35-44$.

Shevade, V. S., Potapov, P. V., Harris, N. L., \& Loboda, T. V. (2017). Expansion of industrial plantations continues to threaten Malayan tiger habitat. Remote Sensing, 9(7), 747.

Revised August 2019 